\title{
A adaptação da narrativa-game de Halliday's Easter Egg Hunt para o filme Ready Player One
}

\section{Game-Narrative Adaptation of Halliday's Easter Egg Hunt into the movie Ready Player One}

Fernanda Martins Ferreira de Araujo* Liliam Cristina Marins*

\footnotetext{
" Estudante de Pós Graduação (Mestrado) do Programa Letras Estrangeiras e Tradução, da Universidade de São Paulo. E-mail: araujo.fmf@usp.br.

" Docente Adjunta do quadro efetivo do Departamento de Letras Modernas da Universidade Estadual de Maringá e professora permanente do Programa de Pós Graduação em Letras da referida instituição. E-mail: Liliamchris@hotmail.com.
}

TradTerm, São Paulo, v.38, fevereiro/2021, p. 217-233 
Resumo: 0 videogame fictício Halliday's Easter Egg Hunt, presente no romance Ready Player One (CLINE, 2011), é uma ode ao universo geek da década de 1980, uma vez que apresenta, no formato de Easter Eggs, elementos culturais (principalmente filmes e jogos) da década mencionada. No ano de 2018, o estúdio Warner Brothers lançou a adaptação cinematográfica desse romance, questionando a afirmação de Cline sobre a inadaptabilidade de sua obra. 0 presente trabalho propõe uma análise das soluções encontradas pelos adaptadores, considerados como co-criadores nesta abordagem (HUTCHEON, 2013), ao adaptar a narrativa-game (AARSETH, 1997; 2005) apresentada no livro para a estética cinematográfica. A análise da adaptação demonstrou que tanto a estética cinematográfica (EDGAR-HUNT, MARLAND e RAWLE, 2010; BORDWELL e THOMPSON, 2013) quanto os princípios estruturais de um game nortearam a transformação do meio impresso para o cinematográfico.

Palavras-chave: Adaptação; Cinema; Ready Player One; Cline; Easter Egg Hunt; Videogame.

Abstract: The fictional videogame Halliday's Easter Egg Hunt, described on the novel Ready Player One (CLINE, 2011), is an ode to the geek universe of the 1980s, seeing that it presents, on the format of Easter Eggs, cultural elements (especially films and games) common in the mentioned decade. On the year of 2018, the Warner Brothers Studios premiered the cinematographic adaptation of that novel, questioning Cline's position in relation to the inadaptability of his story. This essay analyzes the solutions founded by its adaptors, considered as co-creators in this approach (HUTCHEON, 2013), when adapting the game-narrative (AARSETH, 1997; 2005) presented in the book to the cinematographic aesthetic. The analysis showed that the film aesthetic (EDGARHUNT, MARLAND and RAWLE, 2010; BORDWELL and THOMPSON, 2013) and the game structural construction guided the transformation from the book into the cinema.

Keywords: Adaptation; Cinema; Ready Player One; Cline; Easter Egg Hunt; Video game. 


\section{Introdução}

Conforme apontam Robert Edgar-Hunt, John Marland e Steven Rowle (2010: 9), a semiótica da linguagem cinematográfica permite a inserção tanto de elementos (áudio)visuais quanto de elementos verbais na obra final, o que garante ao meio maior expansão de sentidos, de possibilidades narrativas e de público. Essa é uma das características que faz do cinema uma arte que dialoga e transita facilmente entre outros meios semióticos.

Nesses movimentos dialógicos, as narrativas ficcionais são construídas dentro dos limites e potenciais de cada meio. Em concordância com os estudos de Lúcia Santaella (2003: 23), a obra de partida não será representada da mesma maneira em meios semióticos distintos devido à linguagem e à estética próprias de cada meio. A cada produção, há, assim, novas possibilidades de construções de sentidos.

Para Henry Jenkins (2009: 141), a motivação para a existência cada vez mais frequente de adaptações para os mais diferentes meios é o consumo e a abertura para públicos antes restritos a um único meio. Especificamente em relação ao cinema, as constantes adaptações de textos literários para as telas permitem o acesso a narrativas originalmente vinculadas ao meio escritoimpresso e comprovam nossa insaciável "fome por narrativas".

Essa "fome por narrativas", de acordo com Álvaro Hattnher (2013: 41), não se materializa apenas em obras tradicionalmente (re)adaptadas, como as peças Shakespearianas, mas também se revela em outras referências e vetores. O filme Cabaret (1972), dirigido por Bob Fosse, por exemplo, não é apenas uma adaptação do musical homônimo da Broadway (MASTEROFF, 1966), como também da peça I Am A Camera (VAN DRUTEN, 1951), que, por sua vez, é uma adaptação do romance Goodbye to Berlin (ISHERWOOD, 1939), ou seja, a adaptação não acontece unidirecionalmente de uma ponta do vetor a outra, mas apresenta rastros (in)visíveis de outras obras.

Ao considerar que uma obra adaptada é uma "recombinação infinita de (inter)textos" (HATTNHER, 2010: 151), torna-se impossível apresentar uma fidelidade intermidiática, uma vez que os significados produzidos no processo de adaptação são sempre instáveis devido às múltiplas interpretações dos

TradTerm, São Paulo, v.38, fevereiro/2021, p. 217-233

Número Especial - III JOTA

www.revistas.usp.br/tradterm 
adaptadores e às leituras realizadas pelo público-alvo de ambos os contextos (da obra de partida e da sua adaptação).

Essa concepção pós-moderna de adaptação como um processo criativo é defendida por Linda Hutcheon (2013: 29), cujo foco está na (re)interpretação e na (re)criação. Portanto, a proposta deste estudo é analisar a narrativagame, o videogame fictício Halliday's Easter Egg Hunt, presente na adaptação cinematográfica do romance Ready Player One (CLINE 2011), a partir da discussão sobre a interpretação dos adaptadores quanto às referências geeks propostas nos desafios e a ênfase no enredo do game na vida pessoal de Halliday, personagem criadora do próprio jogo. Tal abordagem considera tanto a linguagem quanto a estética cinematográfica.

\section{Adaptação como (re)interpretação e (re)criação: pinceladas teóricas}

As primeiras vertentes dos estudos da adaptação estavam vinculadas predominantemente aos estudos tradutórios, o que, além de limitá-las ao meio escrito, também restringiam o olhar analítico para as transferências e equivalências linguísticas e culturais na passagem de uma língua a outra. Entretanto, com a expansão de adaptações para outros universos simbólicos, meios e vetores, fez-se necessário estudar o processo adaptativo para além do linguístico e do escrito. O campo de abordagem teórica e terminológica responsável por analisar os movimentos transformativos estabelecidos entre um meio semiótico e outro passaram a ser os estudos de tradução intersemiótica e os estudos da adaptação.

Para Thaïs Diniz (1998: 19), os estudos de tradução intersemiótica surgiram da necessidade de observar a passagem entre diferentes sistemas semióticos, com ênfase na mediação de seus signos para a sua nova representação. Nesse sentido, essas traduções transformam os signos verbais da literatura para um novo sistema de signos, sendo necessário adaptá-los por meio dos recursos próprios de cada meio, uma vez que a compreensão do objeto verbal e visual não é a mesma, tanto para o meio de circulação quanto para o observador.

TradTerm, São Paulo, v.38, fevereiro/2021, p. 217-233

Número Especial - III JOTA

www.revistas.usp.br/tradterm 
Já os Estudos da Adaptação ampliam, de certa forma, os estudos intersemióticos, pois partem da utilização dos signos como auxiliares no processo de (re)interpretação e (re)criação de uma obra. Os estudos de Hutcheon (2013) consolidam a noção de adaptação como uma obra autônoma, e não apenas uma reprodução fiel de um original, tornando o adaptador um cocriador da obra adaptada. Para a autora (2006: 108), as escolhas realizadas durante o processo de adaptação refletem o contexto de produção e de recepção, o que, como desdobramento, provoca transformações na obra de partida quando explora a linguagem de um novo meio. Nesse sentido, o produto final se compõe como uma colcha de retalhos das escolhas de seus cocriadores, as quais são inferidas por elementos textuais (neste trabalho, elementos audiovisuais) apresentados a partir da estética e da linguagem de cada meio.

As adaptações cinematográficas, conforme aponta Hutcheon (2013: 118-119), possuem uma coautoria coletiva, visto que há diversos profissionais (diretor, roteirista, figurinista, diretor de arte, etc.) envolvidos na composição da narrativa cinematográfica, sendo, portanto, uma rede de interpretações materializadas em um produto final. Essa coletividade também é corroborada por David Bordwell e Kristen Thompson (2013: 31), os quais (re)afirmam que os elementos fílmicos responsáveis pela experiência cinematográfica são resultados das escolhas realizadas colaborativamente a fim de construir uma narrativa organizada em uma linguagem própria.

Outro ponto a ser mostrado por Hutcheon (2013) sobre a mídia cinematográfica se refere ao modo de engajamento desenvolvido pelo público diante de determinada linguagem. Em A Theory of Adaptation (2013), Hutcheon aponta o cinema como uma mídia performativa, na qual a interação entre público-obra ocorre por meio do modo 'mostrar'. No processo de adaptação de um romance, portanto, as palavras narradas são transcodificadas para a fala, ações e imagens visuais (HUTCHEON, 2013: 69), o que compõe uma nova estética: a audiovisual.

Assim, a análise de uma adaptação deve se pautar, nesse sentido, em critérios menos totalizantes e pautados unicamente no meio semiótico de partida, e mais nas transformações promovidas durante o processo criativo

TradTerm, São Paulo, v.38, fevereiro/2021, p. 217-233

Número Especial - III JOTA

www.revistas.usp.br/tradterm 
que busca atender aos objetivos de produção, circulação e recepção de determinada obra em um novo contexto.

\section{A narrativa-game Halliday's Easter Egg Hunt e seu processo adaptativo e criativo}

Idealizado pela personagem James Halliday (CLINE 2011), criador de OASIS', Halliday's Easter Egg Hunt foi lançado após a sua morte real com o objetivo de determinar quem receberia a sua fortuna, visto que ele não tinha herdeiros. Como o próprio nome aponta, o sistema do jogo se baseia no movimento cultural denominado de Easter Egg, em português, Ovos de Páscoa, surgido da tradição estadunidense de esconder os ovos de chocolate para as crianças procurá-los nas festividades da Páscoa. Os Easter Eggs são elementos 'escondidos' dentro de criações midiáticas (como livros, histórias em quadrinhos, filmes, séries) que revelam uma mensagem ou fazem referência a outro produto cultural.

Halliday cria, assim, o jogo para decidir, entre os milhões de jogadores, quem seria a pessoa digna de receber os direitos de OASIS, uma vez que as quests $^{2}$ criadas referenciam conteúdos midiáticos importantes para a sua formação como designer. Devido a isso, após lançar o jogo, Halliday disponibiliza o Anorak's Almanac, uma espécie de documento com os seus apontamentos a respeito de diversos clássicos midiáticos (videogames, romances de fantasia e ficção-científica, filmes, comic books, entre outros) dos anos 1980, organizado para auxiliar os jogadores nas buscas pelos ovos.

O objetivo do jogo é encontrar: "Três chaves escondidas [que] abrem três portões guardados, e três boas qualidades deverão ser inerentes ao errante avaliado. Quem demonstrar ter os exigidos predicados chegará ao fim,

\footnotetext{
1 Inicialmente OASIS era apenas um jogo de MMORPG (Massively Multiplayer Online RolePlaying Games, ou seja, jogos online com um número significativo de jogadores que controlam um avatar criado por eles próprios dentro de um universo ficcional) criado por James Halliday e Ogden Morrow. Devido ao seu extremo sucesso, torna-se uma plataforma de realidade virtual (RV) que rege a sociedade distópica descrita no livro. Em OASIS, portanto, não se encontram apenas jogos como Halliday's Easter Egg Hunt, como também escolas, bancos, prostíbulos etc.

${ }^{2}$ Espen Aarseth (2005:2) define quest como uma missão direcionada ao jogador, cujo objetivo é realizar uma série de ações para atingir um determinado objetivo concreto e alcançável.
}

TradTerm, São Paulo, v.38, fevereiro/2021, p. 217-233

Número Especial - III JOTA

www.revistas.usp.br/tradterm 
onde o prêmio será alcançado" (CLINE 2018:7, adaptado) ${ }^{3}$. Os jogadores passam, assim, por diversas missões para completar cada quest, ou seja, para conseguir vencer o jogo, os Gunters ${ }^{4}$ precisam: (a) encontrar o local da chave; (b) completar uma missão para conseguir a chave; (c) encontrar o local do portal; (d) completar uma nova missão para o aparecimento do portal; (e) abrir o portal e (f) finalizar a quest. Nesse processo, para a realização de cada missão são apresentadas dicas aos jogadores, normalmente em forma de charadas, as quais podem ser descobertas com o auxílio do Almanac.

O princípio game de Halliday's Easter Egg Hunt se baseia nas quests presentes em jogos do gênero MMOPRG (Massively Multiplayer Online RolePlaying Games). Segundo Espen Aarseth (2005: 2), as quests têm como objetivo o deslocamento de um ponto para outro no jogo a fim de cumprir determinado objetivo. Por meio dessas missões, há uma ampliação da narrativa básica do jogo ao oferecer uma interatividade imersiva maior em seu universo ficcional, revelando múltiplas narrativas existentes (TRONSTAD, 2001 apud AARSETH, 2005: 9).

A interação e a imersão características dos videogames são um dos princípios básicos desta mídia (ROUSE, 2005: 2,4) e se tornam concretos por meio de simulações computacionais. Aarseth (2007: 37) afirma que a simulação se torna parte da experiência do jogo, pois possibilita "compreender casualidades, estabelecer estratégias e efetuar mudanças". Em jogos como os MMORPGs, essa simulação é auxiliada por intermédio do usuário ao construir suas histórias, personagens e enredos, tornando-se coprodutores das narrativas. Assim, a simulação e a interação implicam pensar que jogos são "um tipo de universo diferente, entre ficção e nossa realidade: o virtual" (AARSETH, 2007: 39).

Para caracterizar Halliday's Easter Egg Hunt como um game, o desafio de Cline (2011) foi "como" apresentar a estrutura das quests, a impressão da simulação e, ao mesmo tempo, colocar o leitor do jogo (no caso, o personagem Wade Watts) como agente do processo estrutural da história

\footnotetext{
${ }^{3}$ Tradução de Carolina Caires Coelho. Trecho original: "Three hidden keys open three secret gates, wherein the errant will be tested for worthy traits and those with the skill to survive these straits will reach The End where the prize awaits" (CLINE, 2012: 6).

$4 \mathrm{O}$ nome gunters foi atribuído às pessoas que participam do Halliday's Easter Egg Hunt, uma vez que eles seriam "egg hunters", em português, "caçadores de ovos".
}

TradTerm, São Paulo, v.38, fevereiro/2021, p. 217-233

Número Especial - III JOTA

www.revistas.usp.br/tradterm 
(AARSETH, 1997: 1). A solução encontrada pelo autor foi a utilização dos Easter Eggs para narrar as simulações que a personagem principal enfrentaria ao longo da narrativa. As referências culturais, em ambos os textos (literatura e cinema), estão presentes em todas as fases do jogo, mesmo que em extensões diferentes. Para fins deste trabalho, será exemplificada a diferença entre as narrativas-games apenas a partir do último level ${ }^{5}$ do jogo, The Crystal Key ${ }^{6}$, de forma a destacar as referências culturais presentes em ambos.

No romance Ready Player One (CLINE, 2011), a Crystal Key pode ser dividida em cinco referências: (a) a música 2112, da banda canadense Rush; (b) a música Three Is a Magic Number, da série estadunidense Schoolhouse Rock!; (c) o jogo para Atari The Tempest e a peça homônima de Shakespeare; (d) o filme Monty Python and The Holy Grail (1975); e (e) o jogo Adventure.

Apesar de todas serem de suma importância para a finalização da quest, há um destaque principal à música Three is a Magic Number e ao jogo Adventure. Além de o número três ser recorrente durante a jogabilidade, infere-se que as personagens precisam utilizar três chaves cristais para sua finalização, visto que "sozinho não poderá ser destrancado" (CLINE, 2018: $171)^{7}$. Conforme o objetivo do jogo, o designer testou em cada level uma qualidade diferente em todos os jogadores, partindo do pressuposto de que a última envolveria um trabalho em equipe.

Já em relação ao jogo Adventure (1979), lançado para o console Atari 2600, Halliday (CLINE, 2011: 4), em Anorak's Invitation ${ }^{8}$, descreve que o jogo foi projetado e programado por Warren Robinett, o qual decidiu esconder seu nome em algum momento da jogabilidade, fazendo com que o jogador procurasse uma chave para desbloquear o local secreto com seu nome. Com base nessa sua experiência com Adventure, Halliday decide criar o seu próprio Easter Egg. Para isso, seria necessário encontrar as três chaves para liberá-lo.

Além disso, para desbloquear o jogo Adventure, o gunter necessita descobrir a senha do computador de Halliday. Apesar de o livro não ter como

\footnotetext{
${ }^{5}$ A palavra level refere-se aos níveis existentes no jogo. A palavra em inglês foi mantida devido ao seu uso comum e recorrente no universo game.

${ }^{6}$ Tradução: A chave de cristal.

7 Tradução de Carolina Caires Coelho. Citação original: "and cannot be unlocked alone" (CLINE 2012: 263).

${ }^{8}$ Anorak's Invitation refere-se ao vídeo lançado por Halliday como seu testamento, o qual foi enviado para todos os usuários de OASIS momentos após o anúncio de sua morte.

TradTerm, São Paulo, v.38, fevereiro/2021, p. 217-233

Número Especial - III JOTA

www.revistas.usp.br/tradterm
} 
foco a vida do criador do jogo, Cline (2011) menciona algumas vezes a personagem Karen Underwood, a qual teria sido o grande amor do designer. Apesar de possuir sentimentos muito profundos pela mulher, Halliday nunca conseguiu expressá-los, o que resultou mais tarde no casamento de Karen com Ogden, o cocriador de OASIS. Halliday apaixonou-se por Karen devido aos seus interesses compartilhados em RPGs de Mesa9', tal como Dungeons \& Dragons (D\&D), sendo a senha do computador o nome que ela utilizava nesses encontros: Leuciosa.

Em relação à narrativa cinematográfica, contudo, os cocriadores ampliaram o arco narrativo de Halliday, conforme será discutido na próxima seção. Isso fez com que as quests não fossem apenas odes à cultura geek, mas uma forma de redenção e demonstração do amor entre Halliday e Karen, da amizade entre Halliday e Ogden, e da frustração de Halliday ao vender os direitos de OASIS para que se tornasse uma realidade virtual.

Com essa nova ênfase na narrativa-game, fez-se necessário reduzir a jogabilidade das quests para ampliar o enredo em torno de James Halliday. Portanto, para concluir o game, os jogadores apenas precisam (a) encontrar os locais das chaves; (b) completar missões para adquiri-las e, assim, (d) finalizar as quests. Além disso, essa redução ocorre também devido ao tempo de exibição do filme, visto que há outras tramas e subtramas, como a história de Wade Watts (personagem principal do romance), que envolvem a narrativa cinematográfica como todo.

Em relação à última quest no filme, esta se inicia com a seguinte dica: "se você sabe a resposta do universo, divida-a pelo número mágico e aquilo que você precisa, deseja e almeja se encontrará na fortaleza trágica" (min. 74.54, grifo nosso, tradução nossa). A Resposta do universo faz referência ao romance The Hitchhiker's Guide to the Galaxy (ADAMS, 1981), o qual tem a emblemática noção que 42 seria a resposta do universo ${ }^{10}$; enquanto the magic

\footnotetext{
${ }^{9}$ Considera-se RPGs de Mesas um gênero de jogo, os quais consistem na interpretação de personagens (vide o nome role-playing) por um grupo de pessoas. É geralmente jogado com dados, miniaturas e um tabuleiro. Cada jogo desse gênero, como o supracitado D\&D, possui um sistema de regras distinto.

10 O número 42 é a resposta da Ultimate Question (Pergunta Fundamental) calculada pelo Pensador Profundo (personagem da saga), um computador projetado para fornecer a resposta para a vida e o universo. Disponível em: <https: / / hitchhikers.fandom.com/wiki/Deep_Thought>. Acesso 10 janeiro de 2021.

TradTerm, São Paulo, v.38, fevereiro/2021, p. 217-233

Número Especial - III JOTA

www.revistas.usp.br/tradterm
} 
number, assim como no livro, retrata a música Three Is A Magic Number, da série televisiva estadunidense Schoolhouse Rock!. A divisão de 42 por 3 aponta para o setor quatorze, onde está localizado o Anorak's Castle no Planeta Doom, referência ao jogo Doom (1993).

Ao entrar no castelo, o jogador se depara com um Atari 2600, no qual precisa jogar Adventure (Figura 1), retomando os passos para encontrar o Easter Egg para finalizar, assim, a última missão. Após conseguir o Easter Egg em Adventure e abrir o último portal com as três chaves (Copper, Jade e Crystal), o jogador entra em uma sala com diversas riquezas (Figura 2) aparentes e Anorak o encoraja a assinar um documento para recebê-las (min. 117). 0 gunter, no entanto, precisa recusar a assinatura dos documentos, uma vez que esse seria o último arrependimento de Halliday. Interessante apontar que a entrega do Easter Egg ocorre no quarto de infância de James Halliday (Figura 3), no qual há referências tanto aos elementos culturais citados e descritos ao longo do filme, quanto àqueles que Cline menciona em seu livro, a exemplo do poster do videogame Joust na parede esquerda, o qual aparece no primeiro level do romance.

Com essa breve discussão de como a narrativa Halliday's Easter Egg Hunt foi construída na mídia cinematográfica, percebe-se que outra solução encontrada pelos cocriadores da adaptação foi a apresentação das referências culturais em imagens ao longo do filme. Conforme demonstra a Figura 3, além do pôster de Joust, há, em seu lado direto, um pôster com um desenho da Excalibur, que remete às lendas arturianas. Infere-se que essa decisão de mostrar os Easter Eggs tem como base a linguagem do cinema, conforme mencionado na seção anterior, já que recursos audiovisuais são utilizados para transcodificar descrições e narrações realizadas no romance. Além disso, ao trazer esses intertextos de maneira implícita, compreende-se que a adaptação procura enfatizar os elementos do Easter Egg com o objetivo de fazer com que o espectador os perceba, criando, assim, uma espécie de interação maior entre o público e a obra fílmica.

TradTerm, São Paulo, v.38, fevereiro/2021, p. 217-233

Número Especial - III JOTA

www.revistas.usp.br/tradterm 
Figura 1 - Jogar Adventure no Atari 2600 (min. 107.19). ${ }^{11}$

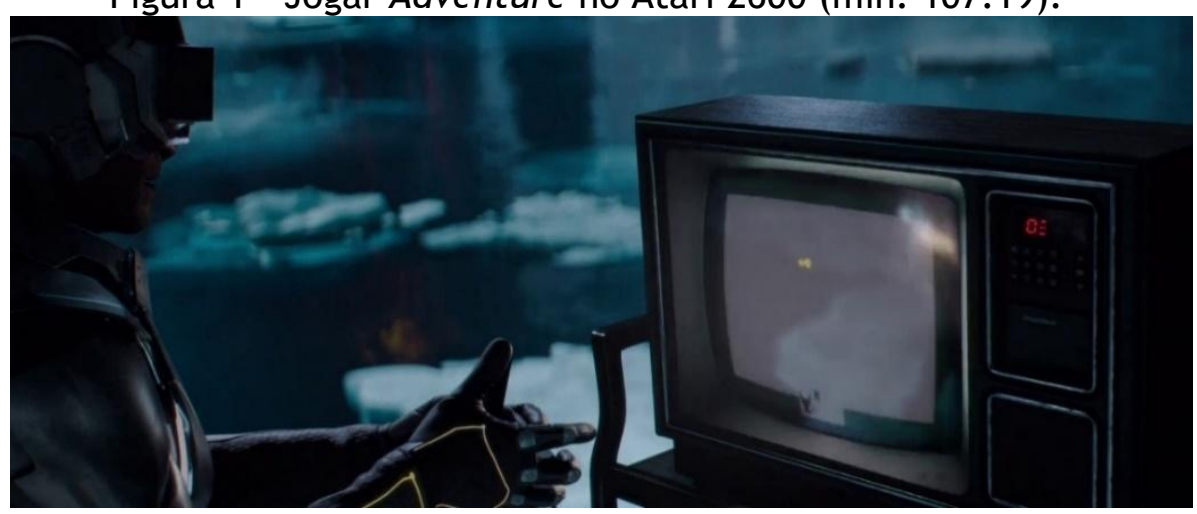

Figura 2 - (Não) assinatura do contrato de OASIS (min. 118.09).

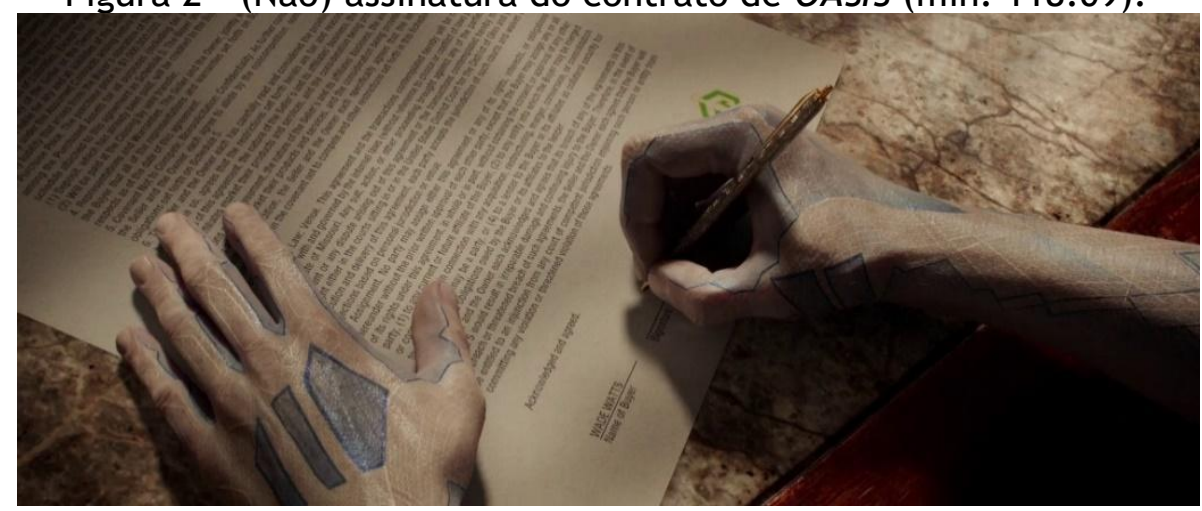

Figura 3 - Quarto de James Halliday (min. 119.19).

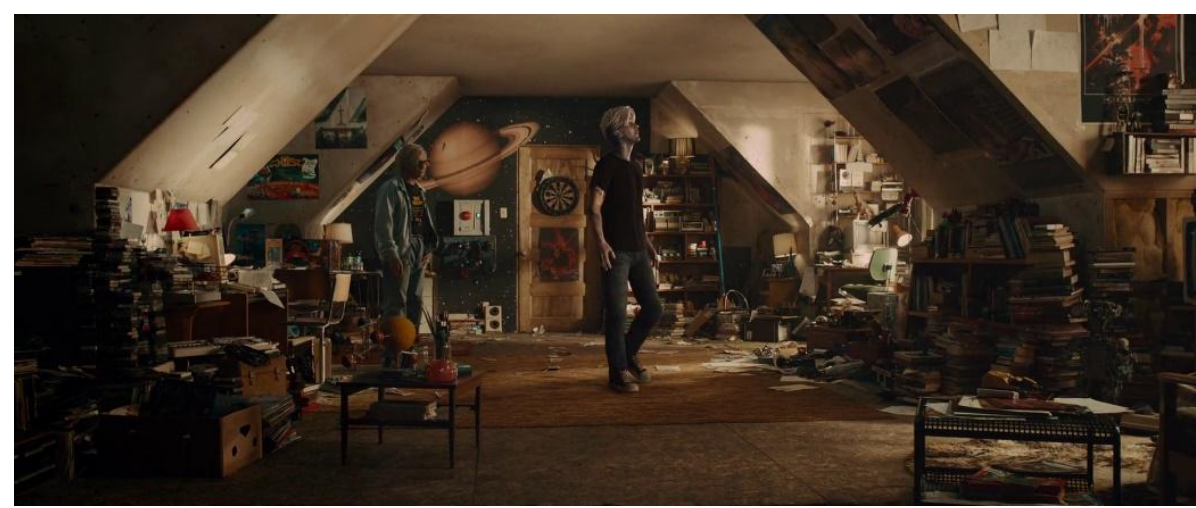

As diferenças entre as quests e levels de ambas as narrativas estão presentes na estrutura, nas referências utilizadas e na composição relacional com a figura de James Halliday. No romance, Halliday Easter Egg Hunt serve como uma porta de entrada para os elementos culturais geeks de 1980, ocorrendo pouca relação da narrativa-game com o universo ficcional distópico

11 FIGURAS 1 a 3: Extraídas de READY PLAYER ONE. Direção: Steven Spielberg. Produção: Steven Spielberg. Roteiro: Zak Penn e Ernest Cline. Los Angeles: Warner Brothers, c2018. 1 DVD (140 min), widescreen, color. Produzido por Warner Video Home. Baseado na novela "Ready Player One" de Ernest Cline.

TradTerm, São Paulo, v.38, fevereiro/2021, p. 217-233

Número Especial - III JOTA

www.revistas.usp.br/tradterm 
em que Wade Watts vive. No entanto, os produtores da adaptação cinematográfica procuraram ampliar o envolvimento de Halliday no jogo, correlacionando sua narrativa-game diretamente com a sua própria biografia. Assim, como desfecho da narrativa fílmica, a última quest buscou entrelaçar as frustrações da personagem Halliday e sua redenção ao conceder OASIS a um fã de seu jogo.

\subsection{James Halliday e a Jornada do Herói}

Com base em Bordwell e Thompson (2013: 149), a narrativa cinematográfica como sistema formal na obra fílmica é pautada na relação causa-efeito, ou seja, as personagens do filme são agentes de ações e reagem aos eventos por elas criados. Para os autores, "o espectador busca de maneira ativa realizar a conexão entre eventos por meio da causa e do efeito" (BORDWELL; THOMPSON, 2013: 151), sendo importante que os cocriadores da obra busquem uma motivação causal das personagens no enredo. Nesse sentido, ao analisar as narrativas presentes nas obras cinematográficas, considerando tanto suas tramas quanto suas subtramas, torna-se fundamental que 0 espectador compreenda o porquê de as personagens realizarem determinadas ações.

Ao descrever o princípio da criação das personagens cinematográficas, de acordo com os pressupostos de Robert McKee (2006: 6), enfatiza-se a existência de uma verdadeira personagem, ou seja, a personagem principal, que se revela a partir das "escolhas que um ser humano faz sob pressão quanto maior a pressão maior a revelação e mais verdadeira a escolha para a natureza essencial do personagem" (MCKeE 2006: 6). Percebe-se que, apesar de o filme se centrar na subtrama de Wade Watts, devido à narrativa-game, construiu-se um arco do herói na história de James Halliday.

McKee (2006: 110) aponta a mudança da natureza interior da personagem ao longo da narrativa fílmica, sendo que, dentro da função da estrutura, criam-se

pressões progressivamente construídas que forcem o personagem a enfrentar dilemas cada vez mais difíceis, gradualmente revelando

TradTerm, São Paulo, v.38, fevereiro/2021, p. 217-233

Número Especial - III JOTA

www.revistas.usp.br/tradterm 
sua verdadeira natureza, até mesmo chegando em seu eu inconsciente. A função do personagem é trazer à estória qualidades de caracterização necessárias para fazer escolhas convincentes. De forma simples, um personagem deve ser crível [...]. A combinação de qualidades deve permitir que 0 público acredite que 0 personagem poderia agir, e agiria, da maneira que age na tela.

Ao partir desta afirmação, nota-se que o objetivo da adaptação cinematográfica foi revelar a história da personagem Halliday, alterando determinados momentos da sua vida pessoal que só poderiam acontecer ficcionalmente, uma vez que viagens no tempo não existem nesse universo fictício, além de a personagem não estar mais viva. Portanto, a narrativa no filme pode ser entendida como a redenção do herói diante de suas frustrações passadas, as quais são auxiliadas por todos os jogadores de OASIS, uma vez que cada um deles reviverá suas memórias. Com esse diálogo entre ficção e realidade, o usuário entra em contato com a psicologia da personagem James Halliday, deixando de vê-lo apenas como o criador da OASIS; isso serve também como um foreshadowing ${ }^{12}$ para a última quest, que finaliza o arco de redenção da personagem.

A caracterização do personagem Halliday está de acordo com o estereótipo nerd ou geek, isto é, uma pessoa que não possui habilidades sociais (seja no âmbito amigável ou amoroso), mas é inteligente e engenhosa, embora apresente dificuldades de agir em relação aos seus medos e à correção de seus defeitos. Tal caracterização cria uma empatia do jogador para com a personagem, deixando também mais convincente a sua necessidade por uma redenção, uma vez que seus principais arrependimentos, conforme o roteiro fílmico, estão diretamente relacionados às suas construções psicológicas.

Ao levar em consideração as características das personagens protagonistas propostas por McKee (2006: 138-139), ao invés de o personagem Halliday alcançar seus desejos (in)conscientes e torná-los verdadeiros, ele cria um jogo para que outros possam realizá-los no campo das ideias. Novamente, nota-se que a construção da personagem, juntamente com os princípios da

\footnotetext{
${ }^{12}$ Foreshadowing é um recurso literário, utilizado também no cinema, que insinua fragmentos da narrativa que ainda estão por vir.
}

TradTerm, São Paulo, v.38, fevereiro/2021, p. 217-233

Número Especial - III JOTA

www.revistas.usp.br/tradterm 
narrativa-game, está pautada na intencionalidade de OASIS e na construção de Halliday's Easter Egg Hunt.

Além disso, considerando a última quest e a não-assinatura do contrato, o jogo também pode demonstrar uma ênfase em não cometer os mesmos erros do passado. Pode-se citar como exemplo o segundo level, no qual os jogadores devem dar um "leap not taken"13 e convidar Karen para dançar, algo que Halliday gostaria de ter feito em seu primeiro encontro, mas não conseguiu take a leap, possivelmente, devido às suas inseguranças e ao medo da rejeição.

Assim, o criador procura mostrar com seus arrependimentos algumas lições aprendidas ao longo da vida, que seriam a criação e a manutenção de seus laços afetivos por meio da perda de Ogden e Karen. A interpretação que pode ser construída é que Halliday sempre esteve preso ao idealismo ficcional dos jogos, tanto que criou uma ode a eles com OASIS, o qual perde sua funcionalidade social fora desse universo. Essa acepção é comprovada em duas cenas em que Halliday faz referência a Karen pelo nome de sua personagem em D\&D - jogo no qual ambos se conheceram -, ao invés de chamá-la pelo seu nome de nascença.

A partir dessa construção da jornada do herói, o espectador, portanto, compreende as motivações de Halliday ao criar Halliday's Easter Egg Hunt, mesmo que postumamente. Contudo, para além da narrativa cinematográfica, as motivações apontadas conectam o espectador de forma mais profunda com a personagem Halliday, em concordância com a construção de narrativasgames. Conforme aponta Evan Skolnick (2014: 41), as reações e instintos da personagem principais se modificam ao longo da história - do estado de insatisfação em direção a uma redenção - para que o jogador crie uma conexão e interação expressiva com tal personagem.

Em suma, ao caracterizar Halliday como protagonista, tanto a narrativa-game quanto a narrativa cinematográfica apresentaram uma motivação para a produção de um processo criativo além da ode. Nesse sentido, as alterações realizadas pelos adaptadores possibilitaram a

\footnotetext{
${ }^{13}$ A expressão idiomática "(take) a leap of faith" significa, segundo o Free Dictionary, fazer algo mesmo sem a certeza de que dará certo.

TradTerm, São Paulo, v.38, fevereiro/2021, p. 217-233

Número Especial - III JOTA

www.revistas.usp.br/tradterm
} 
construção do arco narrativo mais próximo das mídias cinematográficas e dos videogames.

\section{Considerações Finais}

Focalizar Halliday's Easter Egg Hunt na personagem criadora do próprio jogo não apenas condiz com a estética cinematográfica, como também está dentro dos pressupostos que envolvem a criação da narrativa-game. O herói, personagem principal da narrativa, o qual é controlado pelo jogador, inicia sua história em um estado de insatisfação e incompletude, sofrendo as mudanças mais relevantes no decorrer do jogo. Esse estado provoca uma empatia considerável no jogador que precisa se importar significativamente com o herói ou com qualquer resolução de conflito que faça parte de seu objetivo (SKOLNICK 2014: 41).

Conclui-se que a linguagem cinematográfica, dentro de todas suas especificidades, possibilitou uma construção mais complexa e coerente da realidade em Halliday Easter Egg Hunt. Como obra autônoma, o filme respeitou a estética e a linguagem de seu meio de circulação e expandiu a relação tanto dos leitores da obra de partida quanto de novos espectadores. 


\section{Referências}

AARSETH, E. Doors and Perception: Fiction vs. Simulation in Games. In: Intermédialités: Histoire et théorie des arts, des lettres et des techniques. n. 9, 2007, p. 35-44.

AARSETH, E. Ergodic Literature. In: AARSETH, E. Cybertext: Perspectives on Ergodic Literature. Sample chapter. Baltimore: The Johns Hopkins University Press, 1997. p. 1-15.

AARSETH, E. From Hunt the Wumpus to EverQuest: Introduction to Quest Theory. In: Proceedings, Entertainment Computing - ICEC 2005: 4th International Conference, Sanda, Japan, September 19-21, 2005. Lecture Notes in Computer Science, Springer 2005, p. 1-11.

BordWELL, D.; ThOMPSON; K. A arte do cinema: uma introdução. Trad. Roberta Gregoli. São Paulo: EDIUSP, 2013.

CLINE, E. Jogador Número Um. Trad. Carolina Caires Coelho. São Paulo: LeYa, 2012.

CLINE, E. Ready Player One. New York: Broadway Books, 2011.

Dınız, T. Tradução Intersemiótica: do texto para a tela. Cadernos de Tradução, n. 3, Florianópolis, 1998, p. 313-338.

Edgar-Hunt, R.; MARLAND, J.; RAWLE, S. Basic Film-making: the language of film. London: AVA, 2010.

HATTNHER, Á. Quem mexeu no meu texto: observações sobre literatura e sua adaptação para outros suportes textuais. Revista Brasileira de Literatura Comparada, São Paulo, n.16, p. 145-155, 2010.

HATTNHER, Á. Literatura, Cinema e Outras Arquiteturas Textuais: algumas observações sobre Teorias da Adaptação. Itinerários Araraquara, n. 36, p. 35-44, jan./jun. 2013.

HutCheON, L. A Theory of Adaptation. 2a Ed. New York: Routledge, 2013.

HutCheON, L. Uma teoria da adaptação. Trad. André Cechinel. $2^{\mathrm{a}}$ Ed. Florianópolis: Editora da UFSC, 2013.

Jenkins, H. A cultura da convergência. $2^{\mathrm{a}}$ ed. Trad. Susana Alexandria. São Paulo: Aleph, 2009.

MCKEE, R. Story: substância, estrutura, estilo e os princípios da escrita de roteiro. trad. Chico Marés. Curitiba: Ares \& Letras, 2006.

MCKEE, R. Story: substance, structure, style and the principles of screenwriting. New York: ReganBooks, 1997.

TradTerm, São Paulo, v.38, fevereiro/2021, p. 217-233

Número Especial - III JOTA

www.revistas.usp.br/tradterm 
Ready PLAYer One. Direção: Steven Spielberg. Produção: Steven Spielberg. Roteiro: Zak Penn e Ernest Cline. Los Angeles: Warner Brothers, c2018. 1 DVD (140 min), widescreen, color. Produzido por Warner Video Home. Baseado na novela "Ready Player One" de Ernest Cline.

RouSE, R. Game Design: Theory and Practice. 2. ed. Texas: Wordware Game Developer's Library, 2005.

SantAella, L. Da cultura das mídias à cibercultura: o advento do pós-humano. Revista Famecos. Porto Alegre, n. 22, dez 2003, p. 23-32.

SKoLNICK, E. Video Game Storytelling: What Every Developer Needs to Know about Narrative Techniques. Nova York: Watson-Guptill Publications, 2014.

Recebido em: 15/03/2020

Aceito em: 22/09/2020

Publicado em fevereiro de 2021

TradTerm, São Paulo, v.38, fevereiro/2021, p. 217-233

Número Especial - III JOTA

www.revistas.usp.br/tradterm 